\title{
Board 15: Introducing Students to Engineering by Helping Them RePicture Their World
}

\section{Lynn Mayo P.E., RePicture Engineering, PBC}

Lynn Mayo holds a M.S. in civil engineering from Stanford University and a B.S in civil engineering from Bucknell University. After working for over 30 years as a civil engineer, she became CEO of RePicture Engineering, PBC. RePIcture Engineering is dedicated to increasing interest and diversity in engineering by telling the stories of engineering projects, engineers, and organizations. Through the RePIcture.com site, we are helping students discover careers shaping the future and helping companies attract innovators.

\section{Carolyn Breden Voter, University of Wisconsin-Madison}

Carolyn Voter is a Ph.D. candidate in Civil and Environmental Engineering at University of WisconsinMadison where she focuses on urban hydroecology as part of the Hydroecology Lab with Dr. Steven P. Loheide II. She also currently serves as the project assistant for Water@UW-Madison, an umbrella organization which connects water scholars on the UW-Madison campus and beyond. As a certified instructor for the Software Carpentry Foundation, Voter regularly teaches scientists and engineers best practices for scientific computing by live-coding in a two-day, learner-centered workshop. She completed her Delta Certificate in Teaching, Research, and Learning through the Delta Program at UW-Madison (part of the Center for the Integration of Research, Teaching, and Learning) in January 2018. Voter received her B.S. in Civil Engineering from Bucknell University. 


\section{Work in Progress: Introducing Students to Engineering by Helping Them RePicture Their World}

The RePicture App (RePicture.com) is a new way to introduce students and the public to engineering and interdisciplinary engineering teams. It uses the stories of engineering and engineers to change perceptions of engineering. The App's goal is to increase interest and diversity in engineering and can be used in introductory engineering courses to increase students' persistence.

Research shows that high school teachers and students generally do not understand what engineers do and the public does not know that engineers play a vital role in saving lives. Even engineering students often mistakenly think that most engineers sit alone at desks doing math. They may not fully understand the breadth of engineers' work or its benefits to society. This lack of understanding impacts engineering students' persistence in engineering.

Stories about actual engineers show that engineering is creative, collaborative, and makes a real difference in people's lives. The RePicture App uses engineering projects all around us to tell the stories of how engineering projects are benefiting communities and the teams that make projects come to life. The App also tells the stories of individual engineers, including what they do daily on the job and why they like their job. These stories show how the work done by engineers is shaping our future and introduces students to the many different types of engineering jobs. The App also highlights that all types of people (e.g., women and other underrepresented groups) are successful engineers.

There is no cost to use the RePicture App and it is freely available for any course where students will benefit from learning more about engineering projects or engineers. The App was developed based on a review of research regarding how to increase students', including female students', interest in engineering as a career.

This paper discusses the potential benefits of using the App in introductory engineering courses. Because most of the data currently contained in the App regards civil engineering, we expect civil engineering courses initially will be most interested in its use. During the coming months, more stories will be added for civil engineering and other engineering disciplines. This is a work in progress and our goal is to present research results at a future ASEE conference.

\section{Background}

In 2017, there were 200,668 engineering degrees awarded, and only 17,752 (9\%) of these were civil (compared to 20\% for mechanical) [1]. The U.S. Department of Labor (USDOL), however, projects that by 2024 there will be more jobs for civil engineers than any other engineering discipline. The projected 2024 employment growth rate for civil engineers is $8.4 \%$, which is above the projected growth rate of $4.0 \%$ for all engineering disciplines [2]. Including replacing retiring engineers, USDOL estimates that there will be 25,900 annual job openings for civil engineers between 2016 and 2026 [3]. Yet high school teachers and students generally do 
not understand what engineers do and the public does not know that engineers play a vital role in saving lives [4].

Roughly $40 \%$ of students who begin in an engineering college program migrate out of the engineering major. While this migration rate is similar to other majors [5], if we can help more engineering students persist in engineering, it will increase the number of graduating engineers.

In addition, if we can increase the persistence of women engineering students, we can increase the number of women graduates. In $2017,21 \%$ of engineering bachelor degrees were awarded to women. The percentage for women civil engineering graduates was slightly higher at $25 \%$ [1]. The persistence rate for female engineering students is similar to males, at about $60 \%$ [5].

This paper addresses a potential new approach to energize students about careers in engineering. The RePicture App can be used for any science, technology, engineering, or math (STEM) career or project, but is currently populated mostly with information related to civil engineering.

\section{Expectancy-Value Theory Regarding Engineering Persistence}

Several studies [6], [7], [8] have used the Expectancy-Value Theory, developed by Jacqueline Eccles, to understand the factors influencing students' persistence in engineering. As

Matusovich et al. explains [6], Expectancy-Value Theory suggests that a student's decision to persist is shaped by: 1) their expectancy or belief that they can succeed in engineering (i.e., "Can I do this?") and 2) the value or importance they put on engineering (i.e., "Do I want to do this?").

Expectancy beliefs can include:

- Engineering self-efficacy (i.e., confidence in one's ability)

- Expectations for success in engineering

Value beliefs can include:

- Intrinsic interest (enjoyment of engineering activities or interest in engineering)

- Attainment (importance of doing well in engineering in terms of one's core personal values)

- Extrinsic utility (usefulness in reaching one's short term and long-term goals)

- Relative cost (price of success or failure) [6], [8]

\section{Value Beliefs that Affect Engineering Students' Persistence}

This section provides the recommendations of three research papers that evaluate the influence of value beliefs on students' persistence in engineering. Each paper provides recommendations on how to increase engineering students' persistence, which aligns with the RePicture App.

The purpose of the Matusovich, et al. study [6] was to answer the question "how do engineering students' engineering-related value beliefs contribute to their choices to engage and persist in earning engineering degrees?" The study concluded that value beliefs are very important to a student's decision to become an engineer; therefore, we must focus on value beliefs to increase persistence. The paper concludes with the following paragraph (bold added). 
"The findings from this study suggest a need to increase students' attainment values related to engineering in order to increase persistence. In other words, we can encourage students to stay in engineering by helping them associate a perceived engineering identity with their personal identity and demonstrating the value of this association. Doing this requires an understanding of what students value and then connecting this to one or more of the many different ways of practicing engineering. We must help students understand what it means to be an engineer not only by teaching a variety of engineering skills, but also by exemplifying the breadth of activities engineers perform in their daily work. Perhaps this is another way of saying that engineers work in many varied jobs and situations as they participate in a wide variety of activities. We need to make sure students do not develop a narrow view of engineering that omits activities and goals that might particularly interest them as individuals. We must continually (over all four years) and explicitly reference various possible engineering identities. Authentically exposing students to a variety of engineering career possibilities and activities would create opportunities for students to find such connections. While important for both genders, the lower attainment values among women and greater uncertainty about engineering and engineering abilities found in women suggest it is even more important to develop interest and competence beliefs in women to retain them in engineering fields."

Li, et al. [7] studied both engineering and non-engineering students' perspectives using the Expectancy-Value Theory. The study concluded that value beliefs are the most important component. The paper concludes with the following paragraph (bold added):

"The result of our current study suggests that engineering educators and policy makers should start the reform by putting forth efforts to change students' perspectives about engineering and engineering education. In particular, the statistic analysis in this study reveals that intrinsic value is the most critical aspect in shaping students' opinions about engineering. The other aspect that influences students' decisions in choosing engineering majors is the societal utility value. It suggests that education needs to raise students' awareness of the tremendous contributions engineering and technology have made to the society."

Jones, et al. [8] examined changes in engineering students' expectancy and value beliefs after their first year. The study found that expectancy beliefs are better predictors of academic achievement and value beliefs better predict plans to continue into an engineering career. After the first year of engineering school, both expectancy and value beliefs decreased. The decrease in expectancy belief was expected since during the first year of college, students are transitioning from high school to harder college-level courses. The decrease in value belief was not easy to explain. The paper notes (bold added):

"What is more difficult to explain, however, is the finding that at the end of the year, students reported enjoying engineering less and viewed it as less important and useful than they did at the beginning of the year. One explanation may be that freshmen are idealistic at the beginning of their college careers and that a decrease in beliefs about 
engineering enjoyment, importance, and usefulness is to be expected. Another explanation is that some aspect of the first-year curriculum is negatively affecting these value-related beliefs. If this is the case, one implication would be that, given the wide variation in first-year programs across the United States, it could be useful to examine how the curriculum and specific courses influence students' value-related beliefs.

Research into how specific aspects of the curriculum affect students would be useful for identifying ways to maintain or improve students' beliefs about engineering enjoyment, importance, and usefulness."

The common recommendation from these three studies is that increasing a student's understanding of engineering work (e.g., breadth and benefits to society), may have a positive impact on their value beliefs about engineering. This may lead to more motivation to persist in their engineering education. In addition, the National Academy of Engineering [9] found that the "lack of knowledge about the [engineering] profession is a significant barrier for potential engineers from populations underrepresented in engineering."

\section{Expectancy Beliefs Affecting Female Engineering Students}

Some studies show that women have lower self-efficacy in engineering and math [10], [11]. This can reduce a student's expectancy beliefs and thus reduce their persistence in engineering.

A study by Marx and Roman [12] revealed a possible way to counteract this issue. In this study, female students taking a math exam were also given detailed information regarding the female examiner's exceptional math experience and ability. After reading the biography, female students performed better on the math exam and had higher self-esteem scores than those who did not read the biography. Although the study cautions against extrapolating findings from the laboratory to the real world, it ended with the following statement:

"In the end, increasing the number of female role models in math and engineering classes may allow female students to view the negative gender stereotypes that confront them as surmountable barriers rather than ones that are insurmountable and therefore potentially inspire more women, who may not be initially identified with math, to pursue careers in these academic areas."

Exposing female students to a short biography of a successful STEM woman appears to have changed their expectancy belief.

\section{Introduction to Civil Engineering Classes}

The research cited earlier in this paper suggests that to increase persistence in engineering, we should help students understand the broad array of activities engineers perform, the incredible contributions engineers make to society, and engineering's overall importance and usefulness [6], [7], [8]. In addition, providing female students with biographies (or stories) of successful women in STEM may have a positive impact on female students' persistence [12]. Introduction to civil engineering classes are an opportunity to provide this information and the RePicture App can be a tool for this. 


\section{RePicture App Objectives and Development}

The RePicture App objective is to increase interest and diversity in engineering. Our goal is to test the App's use in civil engineering curriculum and then expand to other engineering and STEM fields. The RePicture App helps students repicture the world around them and view engineering as a career that is shaping the future.

RePicture is a free tool to bring the engineering community together, including high school students, engineering students, professional engineers, and engineering organizations. It was developed based on our review of research and discussions with high school educators, university professors, engineering students, early career engineering professionals, experienced engineers, and CEOs at engineering companies.

We developed the App with the goal to:

1) increase interest in engineering as a career (especially by girls and other underrepresented groups)

2) reduce the number of students dropping-out of an engineering major

3) reduce the large percent of women (compared to men) leaving engineering after graduating

As discussed above, the Expectancy-Value Theory can be used to understand the factors influencing students' persistence in engineering. The reasons high school students do not choose engineering careers are equally complex but often similar. According to the National Academy of Engineering, a major challenge of attracting students to engineering is that we have done a poor job communicating what engineers do and why it is important to society [13]. According to American Association of University Women, stereotypes about engineering negatively affected girls' perceived ability to succeed and their perception of whether they belong in engineering [14].

Based on our review of the literature, there were two reoccurring themes that we determined could be addressed through a widely-shared App:

- High school and university engineering students are not aware of the breadth of engineering and/or its tremendous benefits to society [4], [6], [7], [8], [9], [13], [15], [16]

- Girls don't think they "fit" in engineering, have math stereotype threat, and have lower self-efficacy [10], [11], [14], [17], [18]

To address these issues, we turned to the power of stories. Story telling has a long history of being used to convey information and can help change perspectives [19]. The RePicture App: 
- tells the stories of engineering projects all around us and how these projects benefit society, in order to increase students' (and parents', guidance counselors', teachers', etc.) understanding of the breadth and usefulness of engineers' work

- tells the stories of all types of engineers, so all students can find a successful engineer who "looks" like them. The goal is for the demographics of the engineers on the App to match the demographics of our nation's students

Note that aspects of the RePicture App also address the large number of women that leave engineering after graduating. However, a discussion of this is outside the topic of this paper.

\section{RePicture App Description}

The RePicture App introduces students to engineering projects all around them by highlighting the stories of engineering and engineers. These stories reveal how the work done by engineers shapes our future and introduces students to the different types of engineering jobs. The App is free and can be used for introduction to engineering courses. As information is added to the App, it can also help students find engineering internships and first jobs.

Engineering information in the App is presented in a non-technical way, and includes text, pictures and videos. The App also focuses on jobs that are currently most available to early professionals, based on reviewing hundreds of job postings. All information in the App is linked and categorized into three areas: engineering projects, engineers, and organizations.

Engineering Projects: Engineering projects can be found in the App's Project Profiles. Project Profiles highlight different roles that diverse teams play in bringing engineering projects to life. The App connects users to engineering projects and highlights the many engineering-related specialties that improve our life every day. Figure 1 shows an example of the project explorer screen.

After selecting a project on the project explorer screen, students can find details about that project, including:

- Project pictures

- Project overview

- Who benefits from the project and how

- Environmental considerations

- What is unique about the project

- Links to videos and articles for more information

- Project team members (i.e., who brought the project to life, which links to the engineer's People Profiles discussed below)

Information on who benefits from the project is especially important to help students understand the positive contributions engineers make to society. 
Figure 1: RePicture App project explorer screen, after searching for water related projects

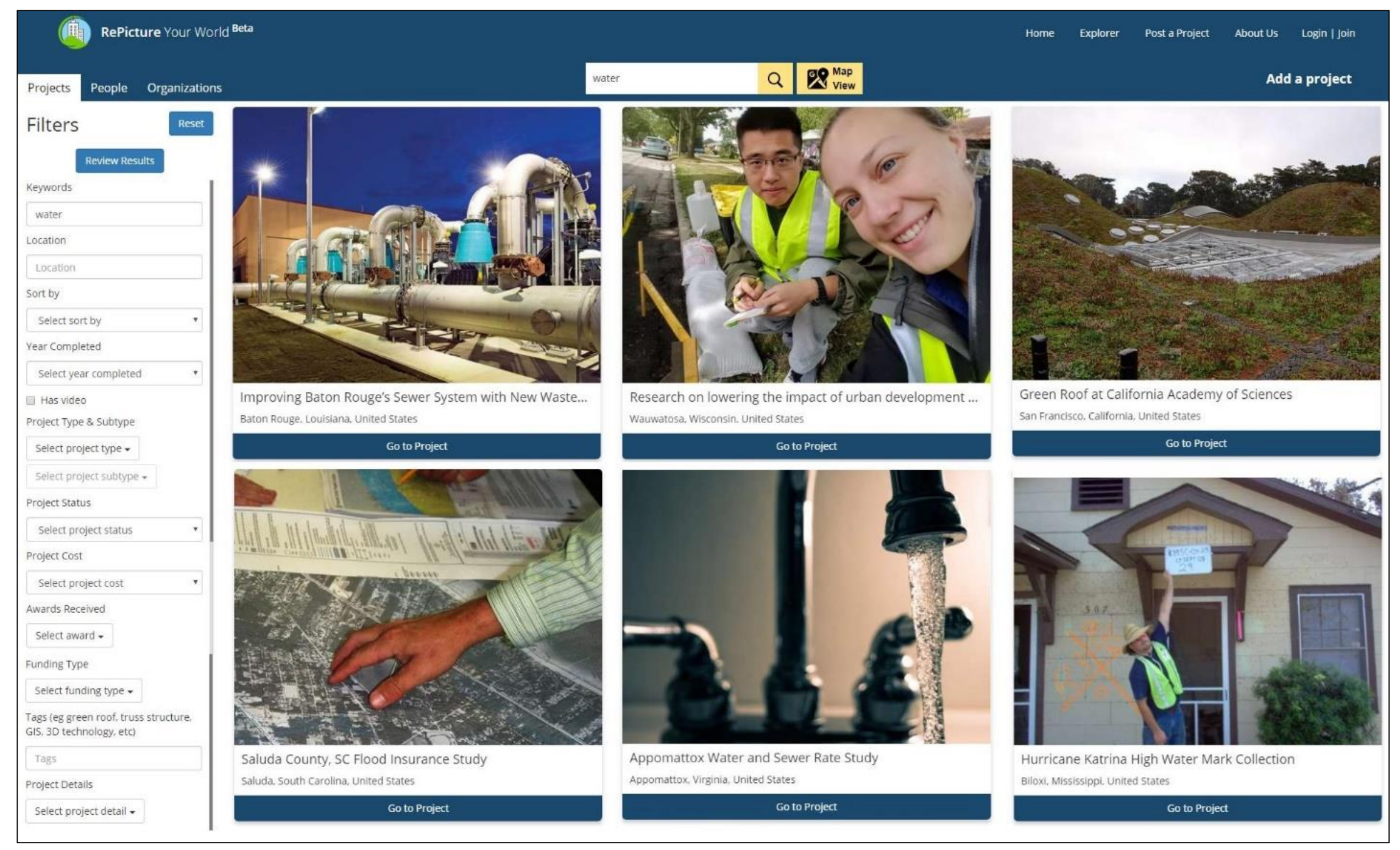


All types of engineering-related projects can be added to the App. Projects are provided by engineering professional societies, engineering companies, engineers, and students. Additional projects are continually being added. While currently the number of projects in the App is limited, the goal is to ultimately have thousands of geo-referenced engineering projects in the App that users can search and find based on their interests.

Engineers (People): The stories of individual engineers are provided on the People Profiles. Students can find engineering role models who "look" like them and envision their own career as an engineer. Figure 2 provides an example of the people explorer page.

After selecting an engineer on the people explorer screen, students can learn about them, including:

- Their education

- What they like about their job

- What college classes they have used the most

- What skills have been most important for their career

- Information on projects they have worked on (and showcased on a Project Page), including:

- Job title at the time of the project

- How many years of experience they had at time of the project

○ Typical day on the project

o What they liked about the project

By viewing the engineer's profile, students can relate their classwork to a profession engineer's work. Students can also see the engineer's career path and how their education helped them succeed.

Currently approximately $50 \%$ of the engineers featured on the App are women and $10 \%$ are African American (compared to the workforce of roughly 13\%). RePicture is continuing to actively recruit stories from underrepresented groups so that they will retain their prominence on the site. Consequently, female students and other underrepresented groups can find engineers who "look" like them and learn about their successes.

Organizations: The Organization Profiles include information on different types of engineering organizations, including engineering-related businesses, nonprofits, and educational institutions. It can also link to Project Profiles and discuss the company's role on projects. General information about an organization may include how it gives back to the community, how it invests in staff, and how it invests in technology. App users can also find information on organizations that are hiring, although currently the number of organizations on the site is limited. 
Figure 2: People explorer screen from RePicture App

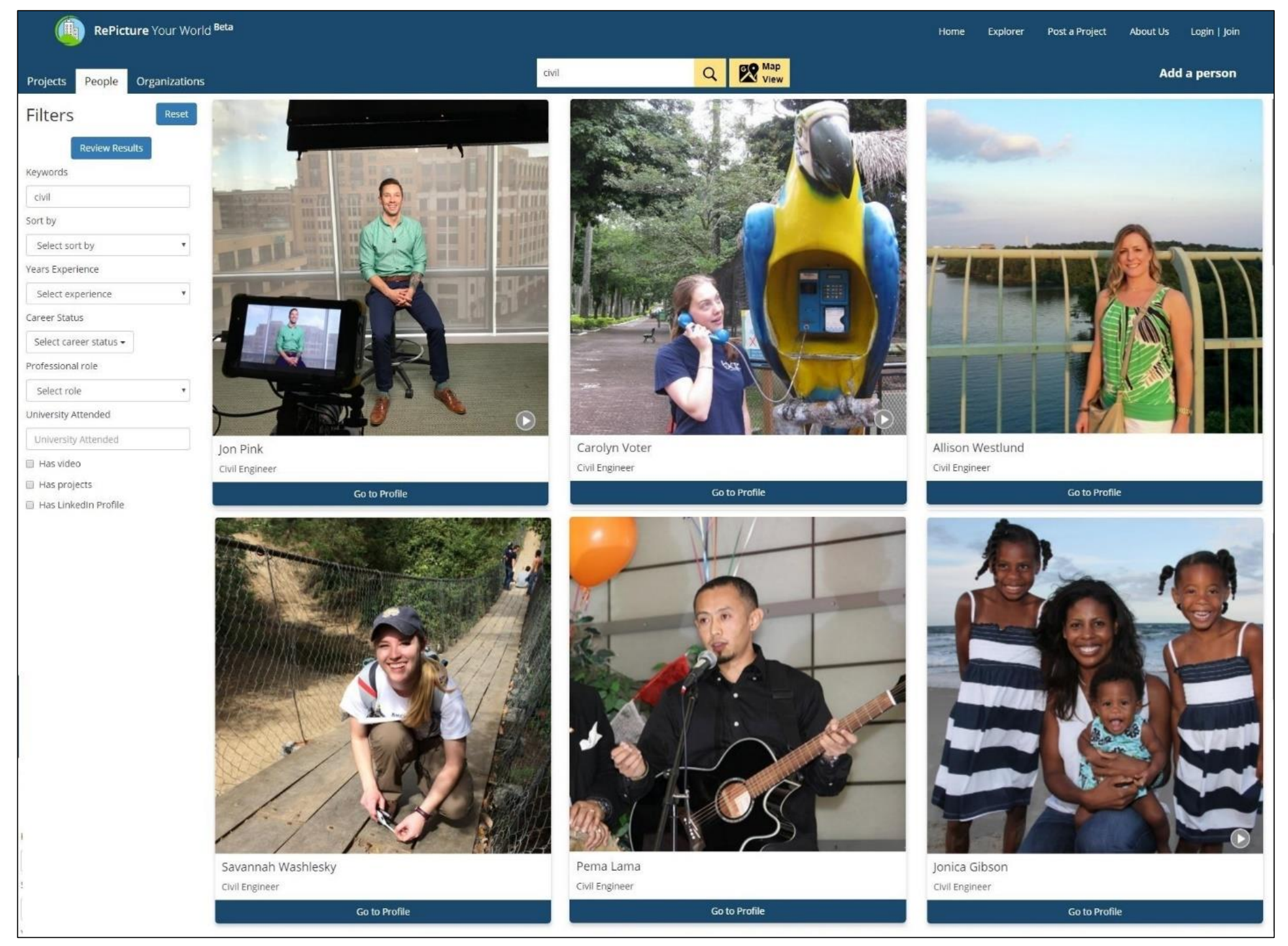


As more information is added to the App, it can be a resource for students to explore, analyze, and discover information about engineering and different engineering specialties. Educators can help students become part of the engineering community by having students upload information into the App. Student contributions may include researching engineering projects, interviewing engineers, or documenting engineering presentations that they attend (e.g., through engineering seminars). Engineering students can also create and update a People Profile for themselves and upload a Project Profile for their research or internship projects. Information that students upload into the App is shared with other students and professionals worldwide.

The RePicture site has full functionality (including the ability to upload information) on a desktop or laptop computer. Information can be viewed on a mobile device. In addition to using the App in the classroom (as discussed in more detail in the next section), students can indicate if they are looking for a job or internship. Companies can search the site for students who are looking for jobs based on location, key words, etc.

All of the above features are free to use, including adding projects, engineer profiles, and basic information about engineering organizations. It is also free to search for companies hiring engineers, including interns and entry level staff. As more companies with job openings are added to the App, it can give students a better sense of the types of jobs that will be available to them. Companies (large or small) have the option to pay a small fee to include their logo and additional information about the company.

\section{Example Classroom Uses}

The RePicture App was designed to be flexible in its use in classes. Some examples of how the App could be used in an introduction to civil engineering class are discussed in this section.

Entering Data into the App: Introduction to civil engineering courses may involve students researching projects, attending presentations by professional engineers, and writing. The RePicture App can be used by having students enter their final product into the App, such as:

- When a class involves presentations from professional engineers, a student or group of students can be assigned to write-up (using the App data format) a project that the presenter discussed. The presenter may be willing to review the student's material before it is entered into the App, which will give the students additional interaction with the professional engineer.

- Students can be tasked with researching an engineering project (including its benefits) or famous engineer and entering the information into the App.

- Students can interview engineering alumni from the college and work with them to create their profile on the App.

These types of writing assignments help students better understand the breadth of work done by 
engineers and their contributions to society. The benefits of requiring students to enter their work into the RePicture App include:

- Inspires students for high quality work: When students know that their work will be shared with others, they are inspired to produce higher quality work. The student products will be posted on the RePicture App and viewed by other students and professionals worldwide.

- Encourages participation from the engineering community: The App provides an additional opportunity for students and professional engineers to work together on a common goal (i.e., to develop material for the App). This interaction with a professional engineer can help students to better understand engineering's importance and usefulness.

- Compiles stories for future classes: Entering material into the App provides a repository of information that the professor can use in future classes. For example, after an alumni's story is added to the App, future students can be inspired by the alumni's story.

Using the App Database: As the RePicture App database of engineering projects and engineers grows, there are unlimited ways it can be incorporated into introductory civil engineering classes. Data on projects, people, and organizations can be filtered (e.g., water projects, engineering careers that use differential equations, or engineers with 2 to 5 years of experience) to find information of specific interest to a class topic or student. Note that data are currently being added to the App and some of these analyses will be more effective after more data are added. Examples of how the App database can be used in a class lesson plan include:

- Reviewing engineering team members who worked on a project to better understand the different civil engineering disciplines (e.g., geotechnical, stormwater, transportation). This will help students understand the vast range of engineering activities.

- Analyzing what classes and skills are most important for different civil engineering specialties, which can help students relate course work to their future jobs.

- Assessing what engineers like about their job or projects, which may improve students' beliefs about the enjoyment, importance, and usefulness of engineering.

\section{Evaluation and Future Plans}

The App can currently be used for lesson plans based on "Entering Data into the App" as discuss in the previous section. This aspect of the App was piloted in a freshman Introduction to Engineering class as part of the Engineering Design for Green Environment (EDGE) Academy in Antioch High School in California. Antioch High is a public school with $81 \%$ minority students and $71 \%$ economically disadvantaged [20]. The pilot was conducted in January and February, 2019. The majority of students in the pilot were male.

For this pilot, approximately 80 students researched an engineering project and entered information about their project into the App. The purpose of the pilot was to test having students use the App. 
During the Antioch pilot, no data was collected on the effectiveness of the App in changing perceptions. The teacher indicated many students appeared to be motivated to provide higher quality work since they knew their research may be published on the App. In addition, three students were interviewed about their experience. Two of the three students indicated they felt they learned more about engineering projects through the assignment.

Based on the Antioch High School pilot, we determined we need to provide students more concise performance outcomes, so students understand when their information is adequate for posting. We also learned that we need to revise our process for reviewing non-published projects and teachers need to schedule time for students to update their work based on review comments.

A second pilot was conducted at a private boarding and day school for girls in grades 9 through 12 in Stevenson, Maryland. The school offers an International Baccalaureate Diploma Program for grades 11 and 12, and Middle Years Program for grades 9 and 10. The pilot was conducted on March 1, 2019 with the entire sophomore class (although due to snow, several students were not in attendance the day of the pilot). For this pilot, girls used the App to read the stories of four women civil engineers and then provided written answers to several questions. The girls were told the goal was for them to conduct beta testing of the App to help refine it. Forty-six girls participated in the pilot, but some students did not answer all questions.

This pilot was not a systematic investigation or research to contribute to general knowledge. The purpose was to beta test the App and identify potential changes to it.

One question asked "Would you be interested in reading similar information for other types of engineers?" Of the 41 girls that answered the question, 38 indicted "Yes," they would like to read about additional engineers. Examples of the 38 positive responses from the girls include:

- "Yes, I never knew very much about any type of engineer but now that I have, it is something that I want to get more involved in and learn about."

- "Yes because if I were to go into an engineering career I would want to make an educated and well informed decision and this would help me."

- "If I were to go into engineering, I would go into civil engineering. It may be because that's mostly what we touched on today, but civil engineering captures my attention."

The girls were asked if they were surprised about anything they read. Of the 43 that answered the question, 36 indicated there was something that surprised them. Their answers were categorized. The Table 1 summarizes the most common responses. 
Table 1: Summary of responses from 41 high school girls regarding what they found surprising after reading the stories of four civil engineers in the RePicture App

\begin{tabular}{|c|c|c|}
\hline $\begin{array}{l}\text { Number of } \\
\text { responses }\end{array}$ & Category Summary & Example responses \\
\hline 12 & $\begin{array}{l}\text { Surprised that } \\
\text { engineering is not only } \\
\text { about math, but } \\
\text { communication and } \\
\text { writing skills are also } \\
\text { important }\end{array}$ & $\begin{array}{l}\text { - "I found it interesting that technical writing was } \\
\text { mentioned as an important skill. When I think } \\
\text { about engineering it would never come to mind" } \\
\text { "That writing was an important skill in becoming } \\
\text { a Civil Engineer. I had always thought that } \\
\text { engineering had nothing to do with writing" } \\
\text { "Communication and writing stills are as } \\
\text { important as STEM skills, so math is not the only } \\
\text { major thing in engineering" }\end{array}$ \\
\hline 9 & $\begin{array}{l}\text { Surprised that engineers } \\
\text { had a life outside of } \\
\text { work, including hobbies }\end{array}$ & $\begin{array}{l}\text { - "I was surprised at how outgoing some of the } \\
\text { people were. Also with the fact that I ... share } \\
\text { some hobbies with them. It really surprised me." } \\
\text {-Although engineers have very busy lives, they } \\
\text { still have time to do the things they love like } \\
\text { spending time with family or the arts" }\end{array}$ \\
\hline 5 & $\begin{array}{l}\text { Surprised at all the } \\
\text { different types of } \\
\text { work/skills of engineers }\end{array}$ & $\begin{array}{l}\text { - "It was intriguing that civil engineering could } \\
\text { cover so many topics and problems" } \\
\text { "It was surprising how many different college } \\
\text { classes can help the career as an engineer and the } \\
\text { variety of required skills because I thought it } \\
\text { would be only one specific sets of skills." }\end{array}$ \\
\hline
\end{tabular}

The girls were also asked which fields in the App they thought were most interesting and should remain in the App. After individually answering this question, they divided into 14 groups of two to four students. Each group identified which three fields they thought were "most interesting and most important to keep on the website." Table 2 provides a summary of the results. 
Table 2: Summary of responses from high school girls regarding what which fields they thought were most interesting and should remain in the RePicture App

\begin{tabular}{|c|c|c|c|c|}
\hline \multirow[t]{2}{*}{ Field } & \multirow{2}{*}{$\begin{array}{l}\text { \# of } 14 \text { groups } \\
\text { indicating } \\
\text { field was in } \\
\text { their Top } 3\end{array}$} & \multicolumn{3}{|c|}{ From 46 individual responses } \\
\hline & & $\begin{array}{c}\text { Interesting } \\
\text { (keep) }\end{array}$ & $\begin{array}{c}\text { No } \\
\text { opinion }\end{array}$ & $\begin{array}{c}\text { Not } \\
\text { Interesting } \\
\text { (delete) }\end{array}$ \\
\hline I choose to be an Engineer because... & 8 & $86 \%$ & $17 \%$ & $0 \%$ \\
\hline $\begin{array}{l}\text { What skills have been most important } \\
\text { to your career? }\end{array}$ & 8 & $85 \%$ & $11 \%$ & $4 \%$ \\
\hline I am... & 4 & $74 \%$ & $22 \%$ & $4 \%$ \\
\hline This is my story & 4 & $74 \%$ & $22 \%$ & $4 \%$ \\
\hline My education has helped me & 4 & $68 \%$ & $28 \%$ & $4 \%$ \\
\hline My typical day at work involves... & 4 & $65 \%$ & $28 \%$ & $7 \%$ \\
\hline I want others to know... & 4 & $63 \%$ & $30 \%$ & $7 \%$ \\
\hline I like my job because... & 3 & $65 \%$ & $24 \%$ & $11 \%$ \\
\hline $\begin{array}{l}\text { What college classes have you used } \\
\text { the most? }\end{array}$ & 3 & $52 \%$ & $28 \%$ & $20 \%$ \\
\hline Hobbies and interest & 0 & $35 \%$ & $48 \%$ & $17 \%$ \\
\hline
\end{tabular}

Note that the "Hobbies and interest" field was the only field where no group thought it was one of the three most important fields and less than $50 \%$ of the girls thought it should remain in the App. However, as shown in Table 1, many girls expressed surprise that engineers had time for hobbies.

Based on this second pilot, we are keeping all of the fields, but we are making some cosmetic changes (e.g., color, layout) to the App.

The ability to create additional lesson plans based on "Using the App Database" is currently limited by the amount of data in the database. One of our priorities is to add more content to the App. Engineering projects and engineers are being continually added. The goal is to have the App ready to be used at the college level in Fall of 2019.

The App can be used for any engineering or STEM major. However, since the App currently contains mostly information on civil engineering, we expect it to first be used in introduction to civil engineering classes. After its evaluation in civil engineering, we will expand its use to other introductory engineering classes.

If funding becomes available, we will evaluate its potential to impact expectancy beliefs (for women and other underrepresented groups) and value beliefs for all students. This is a work in progress and a detailed plan for evaluating its effectiveness will be developed if funding becomes 
available. The evaluation could include measuring changes in Expectancy and Value Believes for engineering students that use the RePicture App versus those that do not. Our goal is to present any research results at a future ASEE conference.

\section{Conclusion}

The demand for civil engineering professionals is expected to increase in the coming decade. Currently about $40 \%$ of first-year engineering students migrate out of engineering [5].

Expectancy-Value Theory suggests that students' decision to persist in engineering is shaped by 1) their expectancy belief that they can succeed in engineering and 2) the value or importance they put on engineering [6].

The RePicture App is a new tool for introductory engineering classes that tells stories about engineering and engineers. It incorporates research on Expectancy-Value Theory, which recommends that we better explain the breadth of work that engineers do and how engineering benefits society (i.e., change value beliefs) [6], [7], [8]. The site also exposes female, and other underrepresented, students to the biographies of successful engineers who "look" like them. This may increase their engineering self-efficacy (i.e., expectancy beliefs) [12].

The App is free for anyone to use and is flexible in its potential use. It was piloted in a high school engineering class and in an all-girls high school. The primary purpose of these pilots was to test using the App in a classroom setting. No formal evaluation of the effectiveness of the App was conducted. However, there was positive feedback from both pilots and it has shaped the development of the App. The App has not yet been tested at the college-level. We are looking for partners to pilot its use in a college-level introduction to civil engineering class. We will also be seeking funding to conduct testing to assess its impact on motivating students to persist in engineering.

\section{References}

[1] B. Yoder, "Engineering by the Numbers," ASEE, 2017. [Online]. Available: https://www.asee.org/documents/papers-and-publications/publications/college-profiles/2017Engineering-by-Numbers-Engineering-Statistics.pdf. [Accessed January 13, 2019].

[2] United States Department of Labor, Bureau of Labor Statistics, "Employment outlook for engineering occupations to 2024," TED: The Economics Daily, October 6, 2016. [Online]. Available https://www.bls.gov/opub/ted/2016/employment-outlook-for-engineeringoccupations-to-2024.htm. [Accessed January 13, 2019].

[3] CareerOneStop, United States Department of Labor, "Careers with Most Openings," [Online]. Available https://www.careeronestop.org/Toolkit/Careers/careers-mostopenings.aspx ?persist=true\&location=US. [Accessed January 13, 2019].

[4] National Academy of Engineering, "Changing the Conversation," 2008. 
[5] M. W. Ohland, S. D. Sheppard, G. Lichtenstein, O. Eris, D. Chachra, and R. A. Layton, "Persistence, Engagement, and Migration in Engineering Programs," Journal of Engineering Education, pp. 259- 278, Revised December 2008. [Online]. Available https://onlinelibrary.wiley.com/doi/10.1002/j.2168-9830.2008.tb00978.x. [Accessed January 13, 2019].

[6] H. M. Matusovich, R.A Streveler, and R. L. Miller, "Why Do Students Choose Engineering? A Qualitative, Longitudinal Investigation of Student's Motivational Values," Journal of Engineering Education, pp. 289- 303, October 2010. [Online]. Available:

https://onlinelibrary.wiley.com/doi/10.1002/j.2168-9830.2010.tb01064.x. [Accessed January $13,2019]$.

[7] Q. Li, D. B. McCoach, H. Swaminathan, and J. Tang, "Development of an Instrument to Measure Perspectives on Engineering Education Among College Students," Journal of Engineering Education, pp. 47-56, January 2008. [Online]. Available: https://onlinelibrary.wiley.com/doi/epdf/10.1002/j.2168-9830.2008.tb00953.x. [Accessed January 13, 2019].

[8] B. D. Jones, M. C. Paretti, S. F. Hein, and T. W. Knott, "An Analysis of Motivation Constructs with First-Year Engineering Students: Relationships Among Expectancies, Values, Achievement, and Career Plans," Journal of Engineering Education, pp. 319-336, October 2010. [Online]. Available https://onlinelibrary.wiley.com/doi/epdf/10.1002/j.21689830.2010.tb01066.x. [Accessed January 13, 2019].

[9] National Academy of Engineering, Understanding the Educational and Career Pathways of Engineers. Washington, DC: The National Academies Press, 2018. [Online]. Available https://doi.org/10.17226/25284. [Accessed April 2, 2019].

[10] E. Litzler, S. Jaros, S. Brainard, and S. Metz, "Gender and Race/Ethnicity in Engineering: Preliminary Findings From the Project to Assess Climate in Engineering," American Society for Engineering Education, 2010. [Online]. Available https://peer.asee.org/gender-and-raceethnicity-in-engineering-preliminary-findings-from-the-project-to-assess-climate-inengineering. [Accessed March 6, 2019]

[11] F. Pajares and M. D. Miller, "Role of Self-Efficacy and Self-Concept Beliefs in Mathematical Problem Solving: A Path Analysis," Journal of Educational Psychology, Vol. 86, No. 2, pp. 193-201, 1994.

[12] D. M. Marx and J. S Roman, "Female Role Models: Protecting Women's Math Test Performance," Personality and Social Psychology Bulletin, Vol. 28 No. 0, pp. 1183-1193, September 2002.

[13] C. M. Vest, “The Image Problem For Engineering: An Overview," The Bridge: Linking Engineering and Society, Vol. 41 No. 2, pp. 5-11, Summer 2011. 
[14] C. Hill, C. Corbett, and A. Rose, Why So Few? Women in Science, Technology, Engineering, and Mathematics. Washington, DC: AAUW, 2010.

[15] L. Katehi, G. Pearson, and M. Feder, Eds., "Engineering in K-12 education: Understanding the status and improving the prospects," National Academy of Engineering and National Research Council. Washington, DC: The National Academies Press, 2009.

[16] National Academy of Engineering, "Changing the Conversation: Messages for Improving Public Understanding of Engineering." Washington, DC: The National Academies Press, 2008.

[17] S. Cheryan, A. Master, A. Metzoff, "Cultural stereotypes as gatekeepers: increasing girls' interest in computer science and engineering by diversifying stereotypes," Frontiers in Psychology, February 11, 2015.

[18] R. B. McIntyre, C. G. Lord, D. M. Gresky, L. L. Ten Eyck, G. D. Jay Frey, and C. F. Bond, "A Social Impact Trend in the Effects of Role Models on Alleviating Women's Mathematics Stereotype Threat," Current Research in Social Psychology, Vol. 10 No 9, pp. 116-136, February 9, 2005.

[19] R. Adams, C. Allendoerfer, T. R. Smith, D. Socha, D. Williams, and K. Yasuhara, "Storytelling in Engineering Education," American Society for Engineering Education, 2007. [Online]. Available: https://peer.asee.org/storytelling-in-engineering-education.pdf. [Accessed March 8, 2019]

[20] U.S. News, “Antioch High.” [Online]. Available: https://www.usnews.com/education/besthigh-schools/california/districts/antioch-unified/antioch-high-1779. [Accessed March 9, 2019] 